\title{
LA NECESIDAD DE UNA ESTRATEGIA DE DESARROLLO ALTERNATIVA AL
}

NEOLIBERALISMO

Francisco Alburquerque (*)

\section{INTRODUCCION}

Los conceptos de SUBDESARROLLO y DEPENDENCIA remiten a dos aspectos diferentes de la realidad de los países del denominado Tercer Mundo. Ambos aspectos se refieren, respectivamente, a la desarticulación económica interna en esos países, y a la desigual y subordinada inserción externa de los mismos en el contexto internacional. Se trata de una «doble complejidad estructural» que atenaza y dificulta poderosamente el crecimiento y desarrollo de los países subdesarrollados y periféricos (Palazuelos y Alburquerque, 1990).

Naturalmente, la discusión acerca de las estrategias de desarrollo para estos países (que en lo sucesivo, y para simplificar, denominaré países subdesarrollados) deberá tener en cuenta ambos aspectos, ya que se requieren políticas específicas en cada uno de esos frentes, si es que se pretenden superar los obstáculos al desarrollo.

En lo que sigue se exponen los rasgos sustantivos de tres estrategias de desarrollo diferentes, a saber:

a) la estrategia de integración a la economía mundial según las reglas del denominado «libre mercado», propugnada por el neoliberalismo económico;

b) la estrategia del «Nuevo Orden Económico Internacional», planteada por los países subdesarrollados desde la Asamblea General de las Naciones Unidas en la segunda mitad de los años setenta; $y$

c) la estrategia de la «desconexión» o búsqueda de un desarrollo autónomo mediante la separación selectiva temporal de la inserción dependiente en la economía internacional.

\section{LA ESTRATEGIA DE DESARROLLO PARA LOS PAISES SUBDESARROLLADOS FORMULADA POR EL NEOLIBERALISMO ECONOMICO}

Esta estrategia propugna la integración de estos países a la economía internacional según las reglas del supuesto «libre mercado», mediante el aumento del comercio internacional, los flujos de inversiones extranjeras y otros movimientos de capitales, así como la «ayuda oficial al desarrollo».

(*) Investigador del Consejo Superior de Investigaciones Cientificas (C.S.I.C.)
Las empresas transnacionales, los grandes bancos internacionales y los organismos e instituciones multilaterales como el Fondo Monetario Internacional, el Banco Mundial o el Acuerdo General de Aduanas y Comercio (GATT) constituyen - junto a las reuniones del Grupo de los Sietelos principales foros desde los que se intenta regular el sistema global, en un claro esquema de dominación favorable a los países desarrollados.

La ideología del librecambio actúa también como elemento funcional a dicho esquema de dominación, ya que la mayor apertura a los mercados internacionales facilita también la más fácil penetración de los grandes agentes oligopólicos empresariales.

Pero pese a la difusión de la ideología del liberalismo económico, en la práctica se lleva a cabo un extensivo proteccionismo, destacando la utilización por parte de los países desarrollados de las más diversas medidas económicas y políticas en tal sentido. La tendencia creciente de regionalización en tres grandes bloques económicos a escala mundial en torno a Estados Unidos, Alemania y Japón facilita igualmente el avance del comercio administrado, basado en el relativo poder de negociación de cada país.

Como es bien sabido, otro componente principal de la estrategia del neoliberalismo económico se refiere a la limitación de la intervención económica del Estado, basado en la supuesta superioridad y eficiencia de los agentes privados frente al Sector Público. Pese a ello, las experiencias de desarrollo que alcanzaron mayor éxito en la historia económica reciente muestran la activa, selectiva y estratégica intervención del Estado en dichos procesos de desarrollo, en una interacción eficiente con los agentes privados, sin contraponer de forma maniquea los antagonismos entre éstos y los agentes públicos, ni la existente entre el mercado y el ejercicio de la planificación.

No es, por tanto, el avance de la privatización lo que garantiza el camino más seguro hacia el desarrollo, sino la existencia de una estrategia - concertada socialmente- de introducción de las innovaciones tecnológicas y organizativas en el tejido socioeconómico interno, un ejercicio que requiere tanto de la citada intervención pública como del ejercicio de una regulación consciente - planificación- de todos estos procesos complejos.

No obstante, la estrategia neoliberal empuja a los países subdesarrollados a insistir en una especialización productiva 
primaria de exportación, para lo cual deben facilitar la globalización del gran capital mediante el establecimiento de un clima atractivo para las inversiones privadas, el fomento de la presencia de las empresas transnacionales, la facilitación de la expatriación de sus ganancias, etcétera, sin que de ello pueda derivarse certeza alguna de que se estén sentando las bases de un crecimiento y desarrollo duraderos.

Esta estrategia cuenta con el beneplácito de las clases privilegiadas locales en los países subdesarrollados, las cuales obtienen sus beneficios de la misma, incrementándose de este modo la brecha social interna en estos países, así como la heterogeneidad estructural y la pobreza.

\section{LA ESTRATEGIA DEL NOEI: DISTINTAS REGLAS DE JUEGO PARA LA ECONOMIA INTERNACIONAL}

Las propuestas a favor de un Nuevo Orden Económico Internacional (NOEI) aprobadas en el seno de la Asamblea General de las Naciones Unidas en 1974 reflejan el momento histórico de mayor poder de negociación por parte de los países subdesarrollados frente a los países desarrollados (Alburquerque, 1990).

Con posterioridad, como es bien conocido, los países desarrollados han logrado eludir cualquier compromiso con aquellos planteamientos que, en lo esencial, plantean la necesidad de mejorar la inserción externa de los países subdesarrollados como forma de facilitar sus procesos de transformación productiva internos, y de impulsar el crecimiento económico global de la economía mundial, mediante el estímulo de la demanda protagonizada por los propios países subdesarrollados.

La propuesta del NOEI plantea, entre otras, la necesidad de garantizar precios estables para los productos primarios en los mercados internacionales, la reducción del proteccionismo practicado por los países desarrollados, el acceso a las nuevas tecnologías por parte de los países subdesarrollados, el establecimiento de un código de conducta para las empresas transnacionales, la solución concertada al problema del sobreendeudamiento externo, el establecimiento de una influencia igual de los países subdesarrollados en los organismos multilaterales, el impulso del Sistema de Naciones Unidas para el Desarrollo, etcétera, todo lo cual afectaría favorablemente la inserción exterior de los países subdesarrollados en el sistema internacional, reduciendo así sus elevados niveles de dependencia.

Ello no obstante, esta estrategia no trata tampoco el cambio de las estructuras económicas y sociales internas en los países subdesarrollados, no cuestionándose el status quo social, político y económico de las élites nacionales en esos países $\mathrm{y}$, en definitiva, no planteándose una estrategia para superar los abismos sociales existentes.

Sin duda, y mucho más en un contexto de cambio estructural tan importante como el actual, la mejora de la inserción externa de los países subdesarrollados constituye una cuestión trascendental para desbloquear aspectos sustantivos del desarrollo en los mismos. Ello no obstante, esta estrategia requiere ser completada con otra que enfrente precisamente la desarticulación económica y social internas, así como los enormes problemas acumulados en términos de equidad social.

\section{LA FALTA DE VISION GLOBAL Y DE LARGO PLAZO EN LA ESTRATEGIA NEOLIBERAL}

Los informes de prospectiva que desde hace años vienen presentándose reiteradamente por diversas organizaciones no gubernamentales de reconocido prestigio (véase entre ellos, King y Schneider, 1991, o los informes anuales del Worldwatch Institute), al analizar los diferentes escenarios tendenciales en la economía global, subrayan como fenómenos sustantivos la agudización de los considerables problemas económicos, ambientales y sociales derivados del actual tipo de crecimiento económico, y demandan la urgente adopción de respuestas radicales a los problemas de la pobreza, el efecto invernadero o la carrera armamentista, entre otros.

La crítica que se realiza a las estrategias neoliberales desde esta perspectiva destaca la falta de una visión global y de largo plazo en relación al desarrollo mundial, señalando cómo en su lugar se procede a la exaltación del «libre mercado», la privatización y la sustitución del análisis real por los planteamientos monetarios parciales.

Del mismo modo, el sistema refuerza el sentido de los flujos comerciales, financieros y tecnológicos hacia los propios países desarrollados, con una clara marginación de la mayoría de la población en los países subdesarrollados, exceptuando las élites privilegiadas que en estos últimos sustentan (y se benefician) de dichas orientaciones predominantes.

Sin embargo, este tipo de críticas no entran suficientemente a explorar las características del modelo operativo de corto plazo, esto es, el tipo de políticas públicas que deben implementarse para abordar las tareas de la transformación productiva interna y la equidad social.

Si bien permiten una contestación radical al tipo de crecimiento económico imperante, señalando igualmente la emergencia de nuevos movimientos sociales críticos, se requiere complementar todo ello con las alternativas para el funcionamiento interno en las economías subdesarrolladas, de lo que paso a ocuparme a continuación.

\section{LA ESTRATEGIA DE LA «DESCONEXION»: LA BUSQUEDA DE UN DESARROLLO AUTONOMO Y AUTOCENTRADO EN LA POBLACION}

A pesar de que la denominación de «desconexión» (Amin, 1988) sugiere en su aceptación gramatical una ruptura con las relaciones capitalistas internacionales $y$, consiguientemente, la búsqueda de opciones alternativas en un 
contexto globalizado donde ello parece ciertamente difícil, lo cierto es que tal propuesta está lejos de exponer simplistamente dicha opción, alejándose igualmente de cualquier planteamiento autárquico.

En su lugar, se trata, en mi opinión, de buscar una separación selectiva temporal de la inserción dependiente de la economía internacional, tratando de proteger prioritariamente el proceso de articulación y diversificación productivas al interior de los países subdesarrollados, invirtiendo de este modo la prioridad que la estrategia neoliberal concede a la apertura y orientación hacia los mercados internacionales.

En realidad, ningún proceso de crecimiento basado en el aumento de exportaciones puede sostenerse en el medio y largo plazo (y menos en las exigencias actuales de competitividad internacional) si no es construyendo o recreando internamente un tejido económico y social suficientemente articulado.

La prioridad dada en esta estrategia a la mayor articulación socioeconómica interna contempla igualmente como objetivo básico la adecuada atención a las necesidades básicas de la población (alimentación, vivienda, vestido, salud, educación, etcétera) defendiendo, por consiguiente, la posibilidad de conciliar al mismo tiempo el libro del crecimiento económico, la equidad social y la democracia participativa.

La experiencia muestra que el crecimiento económico no conduce de forma automática a la equidad. De igual modo, también puede señalarse que la equidad no puede alcanzarse en ausencia de un crecimiento sólido y sostenido, lo cual exige un grado razonable de estabilidad sociopolítica democrática que, a su vez, implica disponer de condiciones mínimas de equidad.

Existe, pues, un condicionamiento recíproco entre los objetivos de crecimiento y equidad, de lo que se desprende la necesidad de avanzar hacia ambos objetivos de forma simultánea y no secuencial.

Las argumentaciones conservadoras, sin embargo, efectúan recurrentemente un análisis secuencial bajo la suposición de que tras el logro de determinados equilibrios macroeconómicos se podrán atisbar los logros sociales. Esta tesis, que se resume en que primero hay que crecer, a fin de poder repartir luego los frutos de ese crecimiento a las grandes mayorías (una cuestión ésta que nunca acaba por llegar), se basa pues en la supuesta incompatibilidad entre los objetivos de crecimiento y equidad.

Otro enfoque diferente del problema considera que la mejor manera de conciliar el logro de los objetivos económicos y sociales es abordarlos por separado. De este modo, la política económica se debe orientar a la búsqueda del crecimiento, mientras que la política social debe centrarse en los aspectos distributivos, a fin de compensar o corregir los fallos de equidad. El problema, en este caso, es que los posibles impactos regresivos de la aplicación de la política económica pueden superar los efectos distributivos progresivos de la política social.

Se hace obligado, por tanto, un enfoque integrado, diferente a los dos anteriores, no dualista ni conservador, para plantear simultáneamente las políticas económicas y sociales como aspectos que conjuntamente refuercen la estrategia de desarrollo (Cepal, 1992).

Así hay que buscar políticas económicas que favorezcan no sólo el crecimiento, sino también la equidad; y del mismo modo, hay que destacar en la política social los efectos de incremento de la capacidad productiva, además de la equidad. El aumento del empleo productivo o la inversión en capital humano son ejemplos de este tipo de políticas que contribuyen al mismo tiempo a objetivos de crecimiento con equidad.

La ampliación del mercado interno de bienes de consumo masivo para atender las necesidades básicas, y la búsqueda de la autosuficiencia o seguridad alimentaria interna (como, por otra parte, se realiza en los países desarrollados en este último aspecto) son, por consiguiente, orientaciones fundamentales en esta estrategia de transformación productiva con equidad social.

En el mismo sentido, son igualmente decisivas la introducción de tecnologías adaptadas a la dotación de recursos propios, la adopción de políticas de redistribución de ingresos, las políticas de empleo y las decisivas políticas de capacitación del capital humano.

En todo ello se hace obligada la intervención selectiva y estratégica del Sector Público, a fin de llevar adelante la adecuada selección y orientación de inversiones hacia una industrialización de amplia base, como medio para producir el mayor número de eslabonamientos entre actividades, ramas y sectores del tejido económico interno, aportando los servicios necesarios a la producción en sentido amplio, fomentando el ahorro y la recaudación fiscal, facilitando el acceso a la financiación y la información sobre todas las fases del proceso económico, y construyendo, en suma, todo el conjunto de sinergias necesario para sustentar la competitividad y eficacia necesarias en este objetivo prioritario interno.

La separación selectiva de la inserción dependiente en la economía internacional no es una meta en sí misma, sino una estrategia para impulsar el desarrollo propio. El desarrollo autocentrado se orienta principalmente - como he señalado- a la satisfacción de las necesidades básicas por medio de una transformación productiva interna, con tecnologías apropiadas y adaptadas a la dotación de recursos propios, movilización de ahorros interiores y, especialmente, mediante un control nacional de las nuevas industrias.

El desarrollo de esa industrialización puede llevarse a cabo impulsada por una interacción creativa del Sector Público y los agentes privados, tal como ha sido el caso de los países que lograron mayor éxito en sus procesos de desarrollo reciente. Lo importante es que exista un proyecto propio de desarrollo nacional orientado hacia la calidad de vida de toda la población, y donde las empresas transnacionales no sigan manteniendo, directa o indirectamente, el control de los procesos productivos y de la comercialización.

Como se ve, este tipo de estrategia enfrenta decisivamente las características internas de la desarticulación en los 
países subdesarrollados, complementando los planteamientos realizados en las propuestas por un Nuevo Orden Económico Internacional citadas con anterioridad.

Es indudable que se esboza así un doble frente de actuaciones y políticas necesarias, y la consiguiente conciencia de ello en las fuerzas políticas y sociales capaces de llevarlas adelante, algo que, hoy por hoy, aún permanece más en el terreno de los deseos que en el de la realidad.

La conciencia de las limitaciones existentes en las estrategias de desarrollo aplicadas anteriormente, y la decepción por los adversos resultados de las políticas ortodoxas de ajuste impuesta por los principales países desarrollados y organismos financieros internacionales hacen obligado a los países subdesarrollados la búsqueda de alternativas.

Asimismo no se puede contar con un mejoramiento significativo del clima económico internacional en la década de los noventa; de modo que los países subdesarrollados van a tener que basarse, en mucha mayor medida que en el pasado, en sus propios medios, en su mayor capacidad de integración como grupo, y en una reorientación estratégica de sus políticas de desarrollo, alejándose de las supuestas ventajas de los ajustes neoliberales.

La crisis que se desencadenó en los años ochenta $-\mathrm{y}$ que sigue afectando a la inmensa mayoría de la población en los países subdesarrollados- exige una evaluación cuidadosa de las anteriores estrategias de desarrollo, al tiempo que deben analizarse de igual modo los cambios estructurales e institucionales en la evolución reciente de la economía internacional, así como las bases teóricas de aquellas estrategias de desarrollo y las políticas públicas aplicadas.

Ante la magnitud de las tareas requeridas, no es posible pensar en que las «fuerzas del mercado», esto es, la suma de iniciativas privadas dispersas, puedan asumir tan importantes retos. De ahí que sea obligado un proceso consciente de regulación y/o planificación para el desarrollo, basado en la participación colectiva y democrática.

Antes de abordar las principales dimensiones del imperativo del desarrollo para los países subdesarrollados me ocuparé de señalar la naturaleza y características de las políticas ortodoxas de ajuste y de sus adversos resultados económicos, sociales y políticos en estos países.

\section{NATURALEZA Y EFECTOS DE LA APLICACION DE LAS POLITICAS ORTODOXAS DE AJUSTE}

Los objetivos principales de las políticas de ajuste neoliberal se orientan a mejorar las cuentas externas y reducir la tasa de inflación, al considerarse - desde esa perspectivaque el logro de esos dos objetivos permite sustentar el crecimiento económico a medio plazo.

Los elementos principales de estas políticas de ajuste se ordenan en torno a tres grandes ejes, respectivamente referidos a las políticas de contracción de las demandas, las políticas de expansión de la oferta y las reformas institucionales (García, 1987). a) Las políticas de contracción de la demanda tienen una clara finalidad antiinflacionista, y son llevadas a cabo principalmente mediante medidas de restricción monetaria y crediticia, austeridad presupuestaria y políticas de congelación salarial.

b) Por su parte, las politicas de expansión de la oferta intentan transferir recursos hacia la producción de bienes comercializables en el exterior, lo que implica desvíos de la producción de bienes para consumo interno y reestructuración de la oferta productiva. Para ello se utilizan medidas monetarias y cambiarias, a fin de procurar los necesarios cambios en los precios relativos.

c) Por último, las reformas institucionales que se propugnan (liberalización comercial y financiera, reducción del papel del Estado en la economía, estímulo de la iniciativa privada y el «libre mercado», etcétera) facilitan la actuación de los principales grupos económicos privados, a quienes benefician fundamentalmente estas estrategias.

Otras características de estas políticas son su aplicación como «tratamiento de choque»; el predominio de las políticas macroeconómicas (y dentro de ellas de las políticas monetaristas) en detrimento de las políticas sectoriales y regionales específicas, $y$, en general, el desprecio mayor hacia las actuaciones en el nivel microeconómico y organizativo de la actividad económica real; la no consideración de los condicionamientos externos de las economías (lo cual en una fase de reestructuración radical de la base tecnológica y productiva de la economía mundial constituye un serio olvido); la indiferencia por los adversos efectos sobre la distribución del ingreso y los desfavorables impactos de tales políticas sobre los grupos sociales más pobres, lo que implica, en definitiva, el desprecio por los efectos políticos hostiles a la democracia participativa.

La evidencia empírica existente sobre la aplicación de estos procesos de ajuste muestra que las políticas de contracción monetaria y crediticia conducen a una baja tasa de crecimiento en el corto plazo. Además, si la contracción afecta a los flujos de crédito hacia la inversión, se ve afectada igualmente la tasa de crecimiento económico a largo plazo.

Si además - como es el caso- la aplicación de tales políticas ortodoxas de ajuste coincide con una fase de reestructuración básica de la economía real, entonces todos estos efectos recesivos se ven agudizados.

Precisamente la existencia de esta situación de reestructuración tecnológica y productiva, en plena fase recesiva de la onda larga de la acumulación a escala mundial del capital, hace bastante inoperantes las medidas monetaristas para producir innovaciones en la oferta productiva, dentro de un contexto de creciente competitividad internacional, sobre nuevos parámetros. Se hacen, pues, necesarias medidas en el nivel microeconómico, organizativo y social, esto es, en el plano real del sistema económico.

De cualquier modo, la expansión de la oferta productiva requiere siempre tiempo y nuevos capitales, con lo que se encuentra condicionada a la disponibilidad de recursos fi- 
nancieros adicionales, que estos procesos de ajuste no han facilitado a los países subdesarrollados, quienes - por el contrario - en casi todo estos años atrás han venido siendo aportadores netos de capitales a los países desarrollados.

Por su parte, las políticas de devaluación del tipo de cambio son bastante inoperantes en el caso de países especializados en la exportación de productos primarios, que conocen además, en estos últimos años, importantes cambios estructurales en los mercados internacionales.

En lo relativo a los efectos sobre el crecimiento de las políticas que actúan sobre el tipo de interés hay que señalar que el mantenimiento de altos tipos de interés desde la primera mitad de los ochenta desestimuló la inversión productiva interna en los países subdesarrollados, favoreció la fuga de capitales y multiplicó los pagos por el denominado «servicio» de la deuda externa.

Aún con todo, una reducción de los tipos de interés en momentos de reestructuración tecnológica y productiva en la economía real no parece operar como señalan los manuales convencionales. Los capitales enfrentan en esos momentos la incertidumbre propia de la profunda fase de reestructuración, en la cual no está suficientemente claro el horizonte de ganancias extras como para atraer a la inversión, con lo cual tienen preferencias las aplicaciones especulativas y financieras.

Por otra parte, los efectos de la aplicación de estas políticas ortodoxas de ajuste sobre la equidad distributiva han sido tremendamente adversos, al bajar los salarios reales (incluso cayendo en mayor medida los salarios mínimos que los salarios medios, esto es, afectando más desfavorablemente a los grupos más pobres), y aumentar el desempleo y la informalidad, así como la desigualdad de ingresos.

El impacto ha sido también muy negativo en términos de los niveles de pobreza existente. El recorte de los gastos públicos en salud y educación, los aumentos drásticos en el precio de los alimentos y las políticas fiscales regresivas han agudizado la pobreza en todos estos países.

Asimismo las deficiencias en la educación y capacitación que ello conlleva afectan muy adversamente no sólo en términos sociales, sino también en términos de crecimiento económico, ya que precisamente la capacitación del capital humano constituye un aspecto decisivo en la construcción de las nuevas ventajas competitivas del futuro, dados los importantes cambios tecnológicos a los que se asiste.

Los efectos regresivos del ajuste neoliberal han reforzado, a su vez, el carácter recesivo del mismo, al desmotivar la inversión en los sectores de producción de bienes de consumo básico. En suma, esta modalidad de ajuste ortodoxo basado, en lo fundamental, en una combinación de políticas de devaluación de los tipos de cambio y políticas monetarias y fiscales restrictivas muestra una clara ineficiencia en su aplicación a la realidad de los países subdesarrollados.

En lo relativo a las políticas de devaluación del tipo de cambio, pese a incrementarse los volúmenes de exportación, ello no se reflejó del mismo modo en el crecimiento del valor de las mismas, ante la larga y sostenida caída de los precios de productos primarios en todos estos años.
Dicha caída de los precios de los productos primarios de exportación, de los cuales depende aún en gran medida el mundo subdesarrollado, responde fundamentalmente a los cambios estructurales sustantivos que vienen teniendo lugar en los mercados internacionales de estos productos, amenazados en muchos casos por sustituciones tecnológicas, cambios en las pautas de consumo, incremento de la oferta de algunos de estos productos por parte de los propios países desarrollados, auge del comercio administrado dentro de los grandes bloques económicos y al interior de las empresas transnacionales, proteccionismo agrícola en los países industrializados, etcétera.

Las exigencias del ajuste externo, ante la dificultad de incrementar la entrada de divisas mediante exportaciones, acabó llevando a los países subdesarrollados a la limitación de importaciones, algunas de las cuales son, sin embargo, de naturaleza insustituible, como alimentos, bienes de capital, energía o insumos para producción de medicamentos.

La devaluación, en este caso, lejos de solucionar el problema externo, agudizó el carácter recesivo generado por la contracción de la demanda interna. Del mismo modo, al estimular la producción de bienes de exportación, se desincentivó la producción interna ocasionando insuficiencias de oferta de bienes para el mercado nacional, provocando tensiones inflacionistas adicionales.

Como vemos, las políticas de devaluación del tipo de cambio no resultan suficientes ni adecuadas cuando se dan cambios estructurales en los mercados internacionales que afectan a la demanda de los productos de exportación. En su lugar parece preferible recurrir a controles temporales del comercio internacional, con el fin de asegurar mayor austeridad en las importaciones, sin introducir las distorsiones que generan las variaciones del tipo de cambio en el sistema de precios.

Por lo que se refiere a las políticas monetarias y fiscales restrictivas, ya se ha señalado cómo los altos tipos de interés han desestimulado la inversión productiva, ya sometida, por otro lado, a la incertidumbre propia del período de reestructuración económica global actual.

El objetivo de estabilidad de precios no puede tampoco basarse exclusivamente en políticas monetarias y fiscales restrictivas, siendo necesario complementarlas con politicas de ingreso y establecimiento de controles en sectores clave, por su incidencia en otras variables, y para evitar el traslado de las tensiones inflacionistas.

Igualmente, el objetivo de equidad exige una política de redistribución de ingresos, ya que la simple reactivación económica no implica mejora en la redistribución de los mismos, ni tampoco el crecimiento cuantitativo del producto interno bruto (PIB) señala qué tipo de bienes y servicios son los que están creciendo, a qué costes sociales o medioambientales, o quiénes se benefician de ese incremento.

Asimismo, la reactivación económica que se mide a través de los indicadores habituales del crecimiento del PIB (o del PIB por habitante) no supone la correspondiente mejora de la situación de los grupos más pobres, ya que éstos trabajan, en una gran mayoría, en el sector informal. 
En todo caso, el objetivo de equidad implica reorientar el desarrollo agrícola hacia la búsqueda de una mayor autosuficiencia o seguridad alimentarias, tal como - por otra parte- llevan a cabo los países desarrollados.

Entre las politicas de ingreso son modalidades de interés los programas especiales de empleo, así como los programas de apoyo al sector informal y al sector tradicional productor de bienes de consumo básico.

En el primer caso, los programas especiales de empleo deben buscar la contratación de desempleados o subempleados para proceder a una superior capacitación para la producción de servicios básicos (alimentación, salud, vivienda, educación). En el segundo caso, los programas de apoyo a los sectores informal y tradicional productor de bienes de consumo básico deben tener como objetivo fundamental el incremento de la productividad en dichos sectores, mediante la facilitación del acceso al crédito y la disposición de nuevas inversiones, la introducción de las innovaciones necesarias en los ámbitos de la gestión y organización productivas, la comercialización y la información de los mercados, y en general, el aporte de los servicios de apoyo necesarios a la producción.

Estas políticas, en el medio plazo, tienden además a minimizar las transferencias que deben hacerse para asegurar la satisfacción de las necesidades básicas de toda la población, lo cual constituye un argumento técnico adicional para defender la viabilidad política de la estrategia que se propone.

En mi opinión, pues, un desafío fundamental para los años noventa en los países subdesarrollados es cómo emprender modalidades alternativas de ajuste, a fin de lograr sostener el crecimiento económico en las actuales condiciones de fuerte restricción de divisas, asegurando la equidad social y la sustentabilidad medioambiental, así como la democracia política participativa.

La equidad y la satisfacción de las necesidades básicas necesariamente requieren la redistribución de ingresos. Igualmente, para que el crecimiento sea equitativo y sostenido, la oferta productiva debe adecuarse a la estructura de demanda que surja de la redistribución, maximizando a su vez la generación de empleo productivo.

El crecimiento, por su parte, exige una disminución de la dependencia de los recursos externos, así como — donde ello sea posible - identificar adecuadamente los segmentos de mercados internacionales adonde es posible estimular las exportaciones. Ello no se desprecia, pero no se le sitúa - tal como sugiere el neoliberalismo económico- como el objeto "mágico» que puede proporcionar el desarrollo a estos países. De ahí que tal objetivo quede subordinado, en este caso, a la estrategia prioritaria de mejorar la articulación del tejido productivo interno.

Hay, pues, que redefinir los motores del crecimiento económico, con el fin de lograr mayor autonomía en la provisión de bienes intermedios y de capital; y estimular el mercado interno mediante la redistribución de ingresos, como mecanismo propulsor del crecimiento.
Ambos objetivos se refuerzan mutuamente: la redistribución de ingresos tenderá a incrementar el mercado interno para la mayoría de los sectores productores de bienes de consumo de primera necesidad, los cuales poseen altos eslabonamientos de empleo y producción, como es el caso de los sectores agrícola, agroindustrial, las industrias de bienes de consumo. esta ampliación del mercado interior puede, además, permitir el aprovechamiento de economías de escala en la producción de bienes intermedios, como maquinaria e insumos de otros procesos productivos.

Como podemos apreciar, este nuevo estilo de desarrollo implica aumentar la inversión, particularmente en la cadena productiva vinculada a los sectores productores de bienes de consumo básico. Ello requiere, por tanto, un uso menos intensivo de divisas, así como dar una orientación estratégica a la política económica de corto plazo. No se niega la importancia de los equilibrios macroeconómicos, pero éstos no son exclusivamente los que define el recetario monetarista y, en todo caso, todos ellos deben asegurar el avance hacia el logro de los objetivos estratégicos del desarrollo, nunca impedirlo.

$\mathrm{El}$ aumento de la inversión y, simultáneamente, la redistribución de ingresos implica que ambos esfuerzos deben provenir de los grupos más privilegiados en estos países, lo cual plantea claramente la dificultad política de la puesta en práctica de la estrategia alternativa de desarrollo. Pero si se observa con detenimiento, la continuidad de la modalidad de ajuste neoliberal incrementa la heterogeneidad estructural, la inequidad social y la pobreza, proporcionando un contexto de inestabilidad social y política, sin ofrecer una salida razonable. Por otra parte, el coste principal del ajuste ya viene siendo pagado fundamentalmente por los grupos más pobres.

De este modo, se hace necesario demostrar que la modalidad alternativa de crecimiento con redistribución implica un crecimiento sostenido y con mayor estabilidad social y política. Supone más desarrollo económico y social, y con legitimidad democrática. De ahí la importancia de lograr una concertación social entre los diferentes agentes sociales, a fin de alcanzar un acuerdo sobre las grandes líneas de estas estrategias alternativas.

La concertación social se presenta pues como una propuesta superadora de las dos formas tradicionales de asignación de recursos y distribución del producto, esto es, el mercado y la planificación estatal burocrática. De hecho, la concertación social debe combinar elementos de ambas, al inducir un funcionamiento del mercado - que continúa desempeñando un papel en la asignación de recursos-, pero incluyendo la definición de objetivos estratégicos, la selección de políticas y actuaciones adecuadas, la coherencia de las mismas, la viabilidad técnica y económica, etcétera, todo ello en un ejercicio de planificación consciente.

Adicionalmente, la concertación social ha de buscar la viabilidad política mediante el logro de un acuerdo social, superando el enfoque economicista de la planificación burocrática tradicional. Se trata, pues, de minimizar la incertidumbre sobre el comportamiento de los distintos agentes y 
reducir los costes derivados de la falta de coherencia en los diferentes objetivos socioeconómicos.

Como se señaló, la principal dificultad es política, y remite a la cuestión de cuánto estarán dispuestos a reducir sus niveles de consumo actual los grupos de mayores ingresos, a cambio de un mayor crecimiento con paz social.

Igualmente, otras dificultades adicionales son las de cómo incorporar a la concertación social a los sectores informal y tradicional rural, generalmente los más pobres y con mayor nivel de organización colectiva; y cómo lograr que resulten precisamente más beneficiados en el proceso de concertación estos grupos más pobres, que son los que tienen menor poder de negociación, dada su baja organización colectiva.

Como se señaló, el papel del Sector Público es crucial en toda esta estrategia alternativa: en el fomento y apoyo selectivo a la producción, en la redistribución de ingresos, en la búsqueda de una interacción creativa con los agentes privados, en el aliento y sostén de la concertación social, en la dirección del proceso estratégico de desarrollo, en una palabra.

Se requiere incrementar el ahorro interno, aumentar la recaudación fiscal y reorientar el gasto público, incorporar las tecnologías adecuadas a la dotación de recursos propios, impulsar el análisis de los impactos medioambientales de cualquier opción programada, etcétera, y nada de esto puede ser solucionado por el mercado.

Por último, la presentación internacional de un proyecto de tal naturaleza, debiera merecer el respaldo solidario de la cooperación internacional al desarrollo, a fin de lograr mejores condiciones externas en temas clave como la negociación de la deuda externa, el acceso a las tecnologías adecuadas, u otros.

\section{A MODO DE RESUMEN: LAS DIMENSIONES PRINCIPALES DE LA ESTRATEGIA ALTERNATIVA DE DESARROLLO}

Naturalmente, la discusión sobre las estrategias de desarrollo alternativas deberá ajustarse, en cada caso concreto, a las condiciones de cada país. Ello no obstante, una estrategia de desarrollo autonómico y autocentrado en la población debe tener como punto de partida ciertos principios y objetivos básicos (COMISION DEL SUR, 1990).

La prioridad dada a la satisfacción de las necesidades básicas de la población (seguridad alimentaria, salud, educación, empleo, vivienda) tiene como finalidad fundamental incrementar la capacidad y potencialidad humanas. Esto exige una economía en crecimiento, esto es, un dinamismo suficiente, sostenido temporalmente, y sustentable medioambientalmente.

En este sentido hay que señalar como objetivos principales la modernización de la agricultura campesina, el impulso de una industrialización de amplia base, el aumento de la creación de empleo y la mejora de la competitividad en el doble frente de la mejor articulación del tejido productivo interno, así como en el plano internacional.
La construcción de estas ventajas competitivas debe basarse fundamentalmente en el incremento del conocimiento e información, así como en el establecimiento de la infraestructura y servicios de fomento a la actividad productiva, y no en el recurso tradicional a las ventajas comparativas estáticas, basadas en la explotación de recursos naturales.

La preocupación por la justicia social conlleva la búsqueda de una distribución más equitativa de los ingresos y de los activos físicos y productivos (entre ellos la tierra), lo cual proporciona además los necesarios estímulos desde el lado de la demanda a la producción interna.

El perfeccionamiento del capital humano atiende, como se señaló, tanto a los objetivos del crecimiento como los de la equidad, e inciden en ello medidas en los ámbitos de la salud, alfabetización, enseñanza elemental y profesional extensivas, formación profesional, enseñanza superior e investigación adaptadas a los problemas nacionales, etcétera.

Especial atención en todo ello hay que dedicar al papel de la mujer en los países subdesarrollados, ya que sobre ellas recae desproporcionadamente la pobreza, habiendo tenido que soportar igualmente la principal de la crisis en estos años. Las mujeres desempeñan en los países subdesarrollados una función vital en las actividades productivas, y en la transmisión de conocimientos en las unidades familiares. De ahí la trascendencia de incrementar la atención y recursos a ellas en estos países.

El dominio, utilización y creación de ciencia y tecnología, a partir de los problemas concretos planteados, exige una revisión de los sistemas educativos y de capacitación. El establecimiento de una política científica y tecnológica con prioridades claras, adaptadas a la dotación de recursos propios y a la estrategia de desarrollo nacional, constituye un objetivo principal en este sentido.

El respeto por la diversidad cultural constituye también una exigencia de la estrategia alternativa de desarrollo, aun cuando se es consciente de que todo proceso de desarrollo implica cambios de normas, valores y criterios culturales. Lo importante es que la modernización necesaria no debe ser contraria a la cultura de un pueblo, sino contribuir a su evolución interna.

La imitación del modo de vida y consumo de las sociedades industriales ricas no es compatible, desde luego, con la estrategia de desarrollo alternativa que se propone. Esa forma de vida sólo sería alcanzable por una pequeña fracción de la población, tal como ocurre actualmente. Y como estrategia supondría, por tanto, una utilización tal de importaciones y energía, que afectaría al propio proceso de crecimiento, intensificando las tensiones económicas y medioambientales.

La descentralización de las actividades del Sector Público puede facilitar la identificación de los recursos potenciales de desarrollo desde los ámbitos regionales y locales o municipales, aí como el mejor planteamiento de las demandas sociales y las diferentes iniciativas. La construcción de este Estado más flexible y descentralizado puede suponer así un desarrollo mayor de la propia democracia participativa, concretando asimismo una atención superior hacia los desequilibrios territoriales y urbanos existentes. 
Naturalmente, la democratización de las estructuras políticas y la modernización de la Administración Pública son otro objetivo fundamental. Es necesario desburocratizar el Estado y construir ese Sector Público activo, flexible y eficiente, con nuevas tareas y contenidos a abordar, como los ya citados, creando un entorno institucional de concertación estratégica. En todo ello se hace necesario lograr el mayor grado posible de participación en la sociedad civil.

El camino es complejo y las dificultades no pocas. Pero no se podrá decir que no existe un diseño de las alternativas a las estrategias del neoliberalismo económico.

Entre las conclusiones que pueden derivarse de todo esto una se me antoja fundamental para los lectores de los países desarrollados que aún comparten la sensibilidad solidaria para con los desposeídos, esa inmensa y mayoritaria parte del mundo: las fuerzas políticas progresistas en estos países desarrollados parecen carecer en sus planteamientos cotidianos de una visión global de los problemas que involucra hoy el desarrollo mundial. Continúa predominando una visión "eurocéntrica» o "anglocéntrica» de estos problemas, sin opciones que contemplen al conjunto de la humanidad. $\mathrm{Al}$ igual que frente al problema del efecto invernadero parecemos ciegos ante el subdesarrollo, la pobreza y la desesperación humanas. En su lugar nos dejamos dirigir por visionarios monetaristas y banqueros que nos empujan cada día un poco más hacia los conflictos y la desigualdad.

\section{BIBLIOGRAFIA}

ALBURQUERQUE, F.: «La búsqueda de alternativas al orden económico internacional actual por parte de la periferia», capítulo 11 de PALAZUELOS, E. (ed.): Dinámica capitalista y crisis actual. Akal Universitaria, Madrid, 1990.

AMIN, Samir: La desconexión. Hacia un sistema mundial policéntrico. Madrid, 1988.

CEPAL: Transformación productiva con equidad. Naciones Unidas, Santiago de Chile, 1990.

- Equidad y transformación productiva: un enfoque integrado. Naciones Unidas, Santiago de Chile, 1992.

COMISION DEL SUR: El reto del Sur, prepublicación, 1990.

GARCIA, Alvaro: «Concertación social para superar la crisis: una perspectiva económica», en BUSTELO, E. S.: Políticas de ajuste y grupos más vulnerables en América Latina. Hacia un enfoque alternativo. Bogotá, 1987.

KING, A., y SCHNEIDER, B.: La primera revolución mundial. Barcelona, 1991.

PALAZUELOS, E., y ALBURQUERQUE, F. (coord.): Estructura Económica capitalista internacional. El modelo de acumulación de postguerra. Madrid 1990.

PROGRAMA DE LAS NACIONES UNIDAS PARA EL DESARROLLO (PNUD): Desarrollo humano. Informes, 1990, 1991 y 1992. Bogotá, Colombia.

SISTEMA ECONOMICO LATINOAMERICANO (SELA): Desarrollo industrial y cambio tecnológico. Políticas para América Latina y el Caribe en los noventa. Caracas, 1991.

STRAHM, R. H., y SPRING, U. O.: Por esto somos tan pobres. Centro Regional de Investigaciones Multidisciplinares. UNAM, Cuernavaca, México, 1990.

WORLDWATCH INSTITUTE: La situación del mundo. Madrid, 1991.

\section{RESUMEN}

A través de la discusión de las tres principales estrategias de desarrollo más recientes: 1) la integración neoliberal al mercado mundial a través del libre mercado; 2) la estrategia del Nuevo Orden Económico Internacional propuesta por los países del Tercer Mundo, y 3) "la desconexión", Alburquerque trata de buscar otra estrategia alternativa de desarrollo capaz de combinar crecimiento económico con equidad y justicia social.

\section{ABSTRACT}

Through the discussion of the three main strategies of development more recently proposed: 1) the neoliberal integration to the world market through the mechanisms of the free market; 2) the strategy of the New International Economic Order propugned by the Third World; and 3) the "disconnection" strategy, Alburquerque poses the question in the search of another alternative strategy of development which combines economic growth with equity and social justice. 